\title{
OPERATION MANAGEMENT USING ITIL AND COBIT FRAMEWORK
}

\author{
Joaquina Marchão ${ }^{1}$ \\ Leonilde Reis ${ }^{2}$ \\ Paula Ventura ${ }^{3}$
}

DOI: https://doi.org/10.31410/ITEMA.2020.201

\begin{abstract}
Information and Communication Technologies management is now increasingly challenging in a highly digital and connected world, with different services emerging for different clients with heterogeneous infrastructures, software, assets, different service requirements, security risks increasing, organizational structures not flexible to adjust. These are some of the variables to manage in Information and Communication Technologies departments. This paper aims to present a literature review to support the design of an approach for service operation management in a medium-sized organization, to improve operational efficiency, cost optimization and stakeholder satisfaction, relevant topics in any organization strategy. The applied methodology includes a literature study related with the frameworks Control Objectives for Information and Related Technology (COBIT) and Information Technology Infrastructure Library (ITIL). The main results underlying the literature review were based on the use of keywords in the subject domain.
\end{abstract}

Keywords: ITIL, COBIT, Service operation, Business process, ITSM.

\section{INTRODUCTION}

I nformation and Communication Technologies (ICT) Management in an organizational context can enhance or limit business development. In this context, the alignment between the organization's management and governance and the ICT department is considered essential. Medium-large size organizations are faced with difficulties underlying greater complexity in the daily service operation management and related processes. Towards improvement, it's important to implement universally accepted ICT management frameworks such as IT Infrastructure Library (ITIL) and/or Control Objectives for Information and Related Technology (COBIT). ITIL is highly used in organizations worldwide to align ICT with business needs through the management of service lifecycle (OGC, 2007).

The stages of the service life cycle are: Service Strategy, Service Design, Service Transition, Service Operation and Continual Service Improvement. COBIT is used to align the management and the governance of IT departments with the company goals. To be competitive, companies must implement information technology that is oriented to customers and stakeholders (Raharjana, Susmiandri \& Justitia, 2018). Service operation is the ITIL stage in which the service quality is perceived by customers and stakeholders. This stage focuses on providing effective and efficient operational services to deliver the required business outcomes and value to the customer (OGC, 2007). ITIL bundle established best practices to support the

Universidade do Algarve, Portugal

Polytechnic Institute of Setúbal, Portugal

Universidade do Algarve, Portugal 
tasks of Information Technology (IT) service operating (Kubiak \& Rass, 2018). Real-life IT support organizations usually implement very complex organizational, structural, and behavioral processes according to strategic objectives defined at the business management level (Bartolini, Stefanelli \& Tortonesi, 2013).

Business processes are more and more dependent on ICT. A process consists of a coordinated set of activities using resources and capabilities to produce an outcome, which, directly or indirectly, creates value for an external customer or stakeholders (OGC, 2007). This paper aims to present a literature review to support the design of an approach for service operation management in a medium-sized organization. The structure of this paper has four sections. The first section is the introduction to the research theme. The second section presents the Research Methodology. In the third section, the results are discussed and in the last one, the fourth, conclusions are presented and recommendations are explained.

\section{RESEARCH METHODOLOGY}

The research approach used is a literature review, began by planning review, identifying the needs and formulating questions and objectives. Next phase allows to define parameters and criteria, generate and refine keywords. The following step on this phase is conduct research and obtain studies, evaluate and record. In a loop process, these two steps will be applied until the achieve the desired results. The last phase is the report review.

\subsection{RESEARCH SCOPE}

The definition of the research process scope is based on the literature found in conference abstracts and journals articles (IEEExplore), conference abstracts and research articles (ScienceDirect), from 2010-2020. The focus is the evaluation of case studies implemented with COBIT and ITIL.

ITIL bundle established best practices to support the task of IT service operation (Kubiak \& Rass, 2018), is the best practices guidance for IT Service Management (ITSM) and has been well accepted by organizations world-wide. ITILv3 presents five stages in the service lifecycle management: Service Strategy, Service Design, Service Transition, Service Operation and Continual Service Improvement (OGC, 2007).

Control Objectives for Information and Related Technology (COBIT) is an IT governance framework; it shows a clear distinction between IT management and IT governance. COBIT19 refers the possibility to define factors and components that should be considered by organizations to build and maintain a governance system: processes, organizational structures, politics, procedures, information flows, culture, ethic and behavior, skills, services, applications and infrastructure of an organization, not only in the ICT domain (ISACA, 2019).

Based on several studies and research it is considered that COBIT and ITIL frameworks are relevant references to support the design of an approach for service operation management in a medium-sized organization, to improve operational efficiency, cost optimization and stakeholder satisfaction. 


\subsection{RESEARCH QUESTIONS}

The formulations of the research objectives are:

Could ITIL and COBIT bring benefit to a medium-sized organization?

Could ITIL and COBIT support implementation of service operation and related business processes?

\subsection{RESEARCH PROCESS}

The process of literature identification used the following resources:

. IEEExplore Digital Library;

. Science Direct;

Based on these two sources, several keywords were used in the search with Boolean operators in the abstract area. The keywords or group of keywords used to find the right literature are: "Implement"; "Case"; "Process"; "Framework"; "Approach"; "Model"; "ITIL"; COBIT; Operation. During the first execution, some similar expressions were detected, it was decided to use all. The search strings were the following:

- In IEEExplore: ("Implement" OR "Case" OR "Process" OR "Framework" OR "Approach" OR "Model") AND "ITIL". It was found 194 studies. Adding AND "COBIT"- to the previous selection, the number of studies decrease to 29. Applying addiction again to the previous selection with - AND "Operation" - (related to ITILv3 service Operation) it results in 2 studies. Adding "medium-size", it resulted in an empty set. It was decided to use the 2 studies previously selected.

- In Science Direct, the article types selected was research articles and conference abstracts; the terms selected were: ("Implement" OR "Case" OR "Process" OR "Framework" OR "Approach" OR "Model") AND "ITIL". It was found 307 studies. Adding - AND "COBIT"- to the previous selection, the number of studies decrease to 100 , showing that is more usual ITIL implementation. Applying another addiction to the previous selection with - AND "Operation" (related to ITILv3 service Operation) it results in 82 studies. Adding "medium-size" (related to the organization size) it results in 26 studies.

The complete string is: $(((()((($ Abstract":Implement) OR "Abstract":Case) OR "Abstract":Process) OR "Abstract":Framework) OR "Abstract":Approach) OR "Abstract":Model) AND "Abstract":ITIL) AND "Abstract":COBIT) AND "Abstract":Operation) AND "Abstract":medium-size).

\subsection{DATA EXTRATION}

The inclusion and exclusion criteria applied to the studies were:

Rejected repeated studies and Rejected studies whose abstracts could not answer the research questions or Scope.

Table 1 presents the results of the research in theme based on the defined criteria.

Table 1. Results of the previous stage

\begin{tabular}{|l|c|c|c|}
\hline \multicolumn{1}{|c|}{ Source } & Studies Found & Candidate & Selected \\
\hline IEE EXplore & 194 & 29 & 2 \\
\hline Science Direct & 307 & 100 & 9 \\
\hline Total & 501 & 129 & 11 \\
\hline
\end{tabular}


Table 1 shows the result of the interactions in online BD to select the studies considered relevant to the development of the framework.

\subsection{RESULT ANALYSIS}

The result of the studies identification was based on the analysis of the following criteria: Publishing Outlets (Conference/Journal); Most productive institutions and Author' academic backgrounds. It is considered that these results can contribute to enrich the framework in development.

\section{RESULTS AND DISCUSSIONS}

Section three presents the result and discussions of publishing outlets, most productive institutions and author' Academic Background.

\subsection{TRENDS CHARACTERISTICS}

Table 2 shows the publishing outlets from selected studies.

Table 2. Publishing Outlets

\begin{tabular}{|c|c|c|}
\hline & Conference/Journal Name & $\#$ \\
\hline Conference & 2019 IST-Africa Week Conference (IST-Africa) & 1 \\
\hline Conference & $\begin{array}{l}2018 \text { 5th International Conference on Behavioral, Economic, and Socio- } \\
\text { Cultural Computing (BESC) }\end{array}$ & 1 \\
\hline Journal & Computer Networks & 1 \\
\hline Journal & International Journal of Accounting Information Systems & 1 \\
\hline Journal & Procedia Technology & 1 \\
\hline Journal & Computer Standards \& Interfaces & 1 \\
\hline Journal & Procedia - Social and Behavioral Sciences & 1 \\
\hline Journal & Computers \& Security & 1 \\
\hline Journal & International Journal of Information Management & 1 \\
\hline & Total & 9 \\
\hline
\end{tabular}

Table 2 identifies conferences and journals where selected studies were presented, it was considered that can add value to the framework in development.

\subsection{AUTHORS' ACADEMIC BACKGROUNDS}

From 32 researchers, they were categorized into 6 department/ knowledge groups. The results show most researchers are from Computer Science groups/departments.

Table 3 shows the author' Academic Backgrounds.

Table 3. Author' Academic Backgrounds

\begin{tabular}{|l|c|}
\hline \multicolumn{1}{|c|}{ Department } & $\#$ \\
\hline Accounting & 1 \\
\hline Computer Science & 16 \\
\hline Software Engineering & 3 \\
\hline Information Systems & 6 \\
\hline Management & 6 \\
\hline \multicolumn{2}{c}{ Total } \\
\hline
\end{tabular}


Table 3 presents the different knowledge areas relevant to the theme. It shows the pertinence of the work proposed in the framework that is under development and its multidisciplinary character.

\subsection{MOST PRODUCTIVE INSTITUTIONS}

Table 4 presents, in an alphabetic order, the institutions considered in the studies selected with the criteria applied.

Table 4. Most Productive Institutions

\begin{tabular}{|l|c|}
\hline \multicolumn{1}{|c|}{ Institutions } & $\#$ \\
\hline Beykent Üniversitesi, Istanbul, Turkey & 1 \\
\hline Federal University of Rio Grande do Sul, Brazil & 1 \\
\hline National Technological University of South Lima, Peru & 1 \\
\hline NHH Norwegian School of Economics, Bergen, Norway & 1 \\
\hline Oregon State University, EUA & 1 \\
\hline Universidad Politécnica de Madrid, Spain & 1 \\
\hline Universitetet i Agder, Kristiansand, Norway & 1 \\
\hline University of Alcala, Madrid, Spain & 1 \\
\hline University of Economics, Prague, Czech Republic & 1 \\
\hline University of Ferrara, Italy & 1 \\
\hline University of Innsbruck, Austria Total & 1 \\
\hline University of Johannesburg, South Africa & 1 \\
\hline University of Manchester, UK & 1 \\
\hline University of Southern Queensland, Australia & 1 \\
\hline University of Tulsa, Oklahoma, EUA & 15 \\
\hline
\end{tabular}

Table 4 shows the relevance of the theme; different institutions around the world are working and producing studies on that subject.

\section{FUTURE RESEARCH DIRECTIONS}

Further research needs to be conducted to align the framework objectives. Literature reviews should be conducted on other sources as well, because this paper only used two sources database (IEEExplore Digital Library and Science Direct). More different sources will enrich the research and knowledge of the implementation of service operation based on ITIL and COBIT.

\section{CONCLUSION}

Due to the need for optimization processes in a medium organization, a framework is being designed, for which a review of the literature is being carried out. The paper presents a literature review from two digital databases (IEEExplore and Science Direct). These publications discuss different aspects of ITIL and COBIT frameworks.

To answer the research questions based on the literature found could be said that ITIL is the most implemented ITSM framework all over the world, the use of IT Services Management 
(ITSM) has provided many positive business impacts; although, there are several issues related to ITSM, such as data quality, process automation, IT as a service broker, etc. (Dharmawan, Sukmana, Wardhani, Ichsani \& Subchi, 2018) and with ITIL processes in place, it becomes considerably easier to resolve and fix the incidents reported (Mahalle, Yong \& Tao, 2018). Besides the benefits, implementing ITIL and COBIT through an organization is challenging and complex, due a lack of alignment between both framework and the fact that literature provides only general guidance (Yamami, Mansouri, Qbadou \& Illousamen, 2016).

\section{REFERENCES}

OGC, Office of Government Commerce, "The Official Introduction to the ITIL Service Lifecycle", London: TSO, 2007.

ISACA, "COBIT 2019 Framework: Governance and Management Objectives". Schaumburg: ISACA, 2018.

I. K. Raharjana, S. Susmiandri and A. Justitia, "Applying IT Services Business Relationship Management on Security Outsource Company" 2018 5th International Conference on Electrical Engineering, Computer Science and Informatics (EECSI), Malang, Indonesia, 2018, pp. 426-431.

P. Kubiak and S. Rass, "An Overview of Data-Driven Techniques for IT-ServiceManagement," in IEEE Access, vol. 6, pp. 63664-63688, 2018, doi: 10.1109/ACCESS.2018.2875975.

Y. Mahy, M. Ouzzif and K. Bouragba, "Supporting ITIL processes implementation using business process management systems," 2016 Third International Conference on Systems of Collaboration (SysCo), Casablanca, 2016, pp. 1-4, doi: 10.1109/SYSCO.2016.7831338.

M. T. Dharmawan, H. T. Sukmana, L. K. Wardhani, Y. Ichsani and I. Subchi, "The Ontology of IT Service Management by Using ITILv.3 Framework: A Case Study for Incident Management," 2018 Third International Conference on Informatics and Computing (ICIC), Palembang, Indonesia, 2018, pp. 1-5, doi: 10.1109/IAC.2018.8780478.

Veronica, A., "Information Technology Service Performance management using COBIT and ITIL framework: A case study. International Conference on Information Management and Technology", (ICIMTech), 2018.

A. El Yamami, K. Mansouri, M. Qbadou and E. H. Illousamen, "Toward a new multi-agents architecture for the adoption of ITIL framework by small and medium-sized enterprises," 2016 4th IEEE International Colloquium on Information Science and Technology (CiSt), Tangier, 2016, pp. 40-45, doi: 10.1109/CIST.2016.7805091.

C. Bartolini, C. Stefanelli and M. Tortonesi, "Synthetic incident generation in the reenactment of IT support organization behavior," 2013 IFIP/IEEE International Symposium on Integrated Network Management (IM 2013), Ghent, 2013, pp. 126-133.

A. Ekanata and A. S. Girsang, "Assessment of capability level and IT governance improvement based on COBIT and ITIL framework at communication center ministry of foreign affairs," 2017 International Conference on ICT For Smart Society (ICISS), Tangerang, 2017, pp. 1-7, doi: 10.1109/ICTSS.2017.8288871.

Veronica and A. Debora Suryawan, "Information technology service performance management using COBIT and an ITIL framework: A systematic literature review," 2017 International Conference on Information Management and Technology (ICIMTech), Yogyakarta, 2017, pp. 150-155, doi: 10.1109/ICIMTech.2017.8273528.

A. Mahalle, J. Yong and X. Tao, "ITIL Processes to Control Operational Risk in Cloud Architecture Infrastructure for Banking and Financial Services Industry," 2018 5th 
International Conference on Behavioral, Economic, and Socio-Cultural Computing (BESC), Kaohsiung, Taiwan, 2018, pp. 197-200, doi: 10.1109/BESC.2018.8697294.

LEKETI, Mpho \& RABORIFE, Mpho. (2019). IT Governance Frameworks and their Impact on Strategic Alignment in the South African Banking Industry. 1-9. 10.23919/ISTAFRICA.2019.8764872.

Nancy Judith Cruz-Hinojosa, José Antonio Gutiérrez-de-Mesa, "Literature review of the situation research faces in the application of ITIL in Small and Medium Enterprises", Computer Standards \& Interfaces, Volume 48, 2016, Pages 124-138, ISSN 0920-5489, https://doi.org/10.1016/j.csi.2016.05.001

Juliano Araujo Wickboldt, Luís Armando Bianchin, Roben Castagna Lunardi, Lisandro Zambenedetti Granville, Luciano Paschoal Gaspary, Claudio Bartolini, "A framework for risk assessment based on analysis of historical information of workflow execution in IT systems", Computer Networks, Volume 55, Issue 13, 2011, Pages 2954-2975, ISSN 1389-1286, https://doi.org/10.1016/j.comnet.2011.05.025

Firoozeh Rahimian, Akhilesh Bajaj, Wray Bradley, "Estimation of deficiency risk and prioritization of information security controls: A data-centric approach", International Journal of Accounting Information Systems, Volume 20, 2016, Pages 38-64, ISSN 14670895, https://doi.org/10.1016/j.accinf.2016.01.004.

Michal Sebesta, "On ICT Services Outsourcing in the Context of Small and Medium Enterprises", Procedia - Social and Behavioral Sciences, Volume 81, 2013, Pages 495509, ISSN 1877-0428, https://doi.org/10.1016/j.sbspro.2013.06.467

Michael Curry, Byron Marshall, Peter Kawalek, "IT artifact bias: How exogenous predilections influence organizational information system paradigms", International Journal of Information Management, Volume 34, Issue 4, 2014, Pages 427-436, ISSN 0268-4012, https://doi.org/10.1016/j.ijinfomgt.2014.02.005.

Sudi Apak, Sefer Gümüş, Zuhal Kurban, „Strategic Dimension of Outsourcing in the Information Technologies Intensified Businesses", Procedia - Social and Behavioral Sciences, Volume 58, 2012, Pages 783-791, ISSN 1877-0428, https://doi.org/10.1016/j.sbspro.2012.09.10561

Jon Iden, Tom Roar Eikebrokk, "Implementing IT Service Management: A systematic literature review", International Journal of Information Management, Volume 33, Issue 3, 2013, Pages 512-523, ISSN https://doi.org/10.1016/j.ijinfomgt.2013.01.004.

Igor Aguilar Alonso, José Carrillo Verdún, Edmundo Tovar Caro, "Case Study of Strategic IT Demand Management in Organizations - Exploratory Results", Procedia Technology, Volume 9, 2013, Pages 900-909, ISSN 2212-0173, https://doi.org/10.1016/j.protcy.2013.12.100.

Michael Brunner, Clemens Sauerwein, Michael Felderer, Ruth Breu, "Risk management practices in information security: Exploring the status quo in the DACH region", Computers \& Security, Volume 92, 2020, 101776, ISSN 0167- 4048, https://doi.org/10.1016/j.cose.2020.101776. 